\title{
Polvos azules, un pigmento de múltiples usos. Aproximación al uso terminológico en los siglos XVII y XVIII
}

Corinna Gramatke | doctora en conservación y restauración de pintura y tallas policromadas de la Hochschuhle für Bildende Künste Dresden (Alemania)

URL de la contribución <www.iaph.es/revistaph/index.php/revistaph/article/view/4342>

\section{RESUMEN}

La terminología técnica en el ámbito del material artístico ha cambiado durante los siglos. Muchos de los antiguos vocablos cayeron en desuso o han variado de significado, complicando así la interpretación de los términos históricos. Polvos azules es uno de ellos. Se encontró primeramente en documentos de los virreinatos españoles a partir del siglo XVII y se solía relacionar con el pigmento azul de azurita $\left(\mathrm{Cu}_{3}\left(\mathrm{CO}_{3}\right)_{2}(\mathrm{OH})_{2}\right)$. Pero las enormes cantidades encontradas y el precio relativamente bajo pusieron en duda esta interpretacion. Sobre la base de estos documentos, este artículo se centra en la literatura tecnológica y económica específica de Europa, comparando las características y aplicaciones descritas. El estudio llevó a la conclusión que el término polvos azules se refiere al pigmento de esmalte, porque el vidrio azul de cobalto pulverizado $\left(\mathrm{K}, \mathrm{Co}(\mathrm{Al}), \mathrm{SiO}_{2}\right.$ ) tuvo muchos más usos en los siglos XVII y XVIII, los que hoy día han caído en el olvido

\section{Palabras claves}

Azurita | Comercio | Diccionarios | Esmalte (Material) | Materiales | Pigmento azul | Terminologías | 


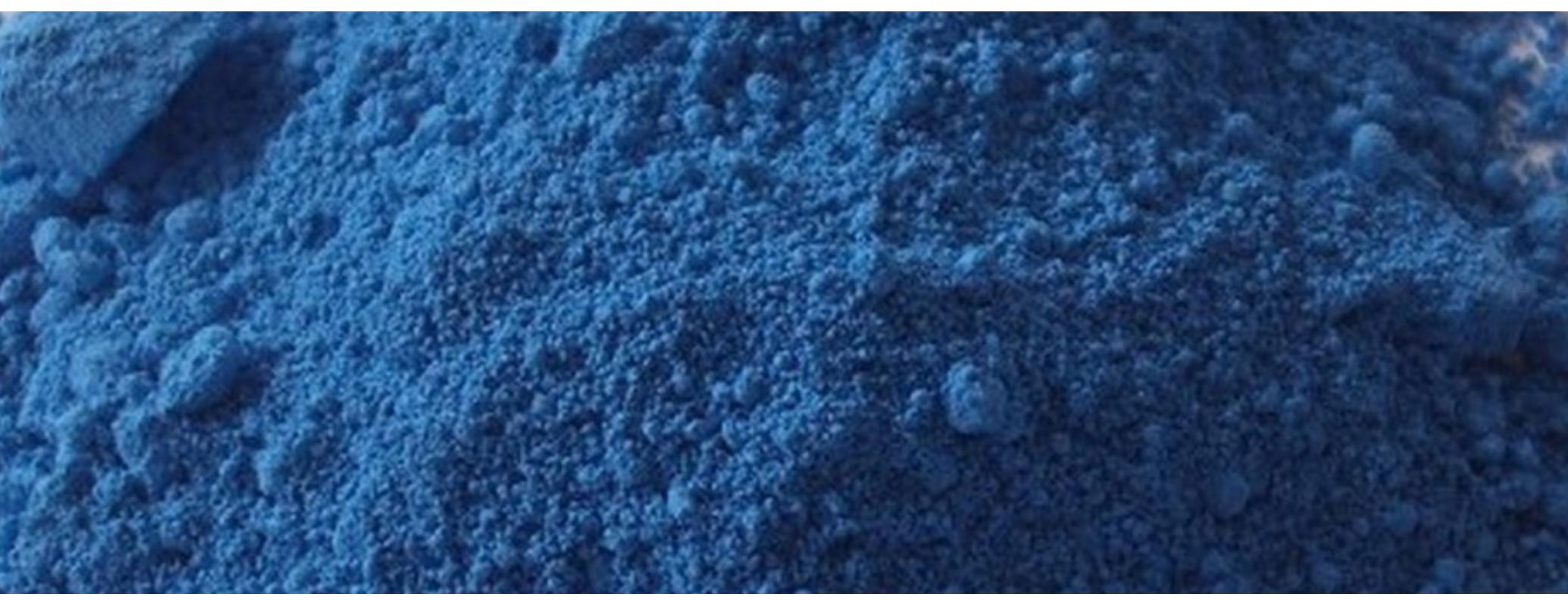

Polvos azules, a pigment of multiple use. Approach to the terminological use in the $17^{\text {th }}$ and $18^{\text {th }}$ centuries

\section{ABSTRACT}

Terminology in the scope of painting materials has changed continuously over the course of centuries. Many of the ancient technical terms have vanished or have suffered a semantic change. This often complicates the interpretation of historical terms. Polvos azules is one of them. The term was initially found in South American documents of the $17^{\text {th }}$ century and was interpreted as azurite $\left(\mathrm{Cu}_{3}\left(\mathrm{CO}_{3}\right)_{2}(\mathrm{OH})_{2}\right)$. But the enormous quantities of polvos azules and the relative cheap price found in archival documents of the $17^{\text {th }}$ and $18^{\text {th }}$ century, cast doubt on indicating azurite. Based on these documents this paper focuses on specific European technical and economic literature, comparing the described characteristics and applications. The study leads to the conclusion that polvos azules refers to smalt, the well known blue pigment, because the pulverized blue cobalt glass $\left(\mathrm{K}, \mathrm{Co}(\mathrm{Al}), \mathrm{SiO}_{2}\right)$ had far more uses very common in $17^{\text {th }} \mathrm{a}$ an $18^{\text {th }}$ centuries, but which have nowadays fallen into oblivion.

\section{Key words}

Azurite | Commerce | Dictionaries | Smalt (Material) | Materials | Blue Pigment | Terminologies |

Cómo citar: GRAMATKE, C. (2019) Polvos azules, un pigmento de múltiples usos. Aproximación al uso terminológico en los siglos XVII y XVIII. Revista PH [en línea], n. ${ }^{\circ}$ 97, junio 2019, pp. 60-87 <www.iaph.es/revistaph/index.php/revistaph/article/view/4342>

Enviado: 27/01/2019 | Aceptado: 03/06/2019 | Publicado: 28/06/2019 


\section{INTRODUCCIÓN}

En el contexto del proyecto de investigación acerca de la producción artística en las misiones guaraní-jesuíticas de los siglos XVII y XVIII en la antigua provincia de Paraguay ${ }^{1}$, surgió el término polvos azules, ofreciendo varias interpretaciones. Este ensayo quiere profundizar en la cuestión.

El proyecto, originado en la Technische Universität München y financiado por la DFG, titulado: La escultura en madera policromada de las reducciones jesuíticas de Paracuaria, 1609-1767. Un estudio de tecnología del arte considerando el aporte de los jesuitas alemanes, consistió en el estudio de las esculturas in situ en los museos en Paraguay y Brasil, y en la investigación en los correspondientes archivos y se centró en la organización de los talleres artísticos, el personal allí activo y las técnicas y materiales empleados (EMMERLING; GRAMATKE, 2019).

La terminología técnica en el ámbito del material artístico ha cambiado continuamente. Muchos de los antiguos vocablos cayeron en desuso, los términos han variado de significado con el tiempo. En cuanto a las fuentes escritas hay que contar con un vocabulario regional, local, o reducido a un solo taller, con las denominaciones del comercio y también, por supuesto, con erratas y fallos ortográficos y copias defectuosas. De allí resultan hoy día, de igual manera, diferencias en la interpretación de los términos históricos. El término polvos azules es uno de ellos. Francisco Pacheco, Vicente Carducho o Antonio Palomino no lo emplean en sus tratados de pintura del Siglo de Oro. Sin embargo, algunos investigadores lo han encontrado en sus pesquisas sobre pigmentos en fuentes literarias de los virreinatos españoles a partir del siglo XVII, más que nada y con mucha frecuencia en documentos mercantiles. Se solía relacionar con el pigmento azul de azurita $\left(\mathrm{Cu}_{3}\left(\mathrm{CO}_{3}\right)_{2}(\mathrm{OH})_{2}\right)$, pero permanecieron dudas debido al precio relativamento bajo y a las grandes cantidades en circulación. El término en sí es bastante genérico y pudo abarcar, y abarcó en las fuentes, cualquier tipo de pigmento azul molido, en forma de polvo, como azurita, índigo, lapislázuli, esmalte y azul de Prusia. El presente estudio es una investigación bibliográfica, basada en diferentes documentos históricos y en fuentes europeas de carácter técnico, económico y comercial que contienen información sobre la producción y la comercialización de pigmentos. Se comparaban entre sí las de Alemania, Francia, Inglaterra y España, lo que permitió concluir que este término a partir del siglo XVII se introdujo en el comercio para el vidrio de cobalto pulverizado ( $\mathrm{K}, \mathrm{Co}(\mathrm{Al}), \mathrm{SiO}_{2}$ ), que además de servir como pigmento azul para los pintores, tuvo una variedad de otros usos, hoy caídos en el olvido.

\section{SURGIMIENTO DEL TÉRMINO POLVOS AZULES Y LA DIVERGENCIA DE INTERPRETACIONES}

En un artículo del año 1999 sobre los pigmentos azules en la pintura sudamericana entre 1610 y 1780, un grupo de químicos e historiadores de arte declaran los términos polvos azules y la azurita como sinónimos. Se trataría del pigmento de origen mineral, compuesto de carbonato básico de cobre. Los autores se basan en fuentes escritas como, por ejemplo, la de León Pinelo, quien, en 1659, en su libro El Paraíso en el Nuevo Mundo, habla de "polvos azules para pintores", extraídos de una mina cerca de Atacama; esto 
corresponde a la azurita, ya que se había detectado en pinturas rupestres prehispánicas cerca de aquel yacimiento. Además, Pinelo habla de polvo azul extraído de Santo Domingo (Hispaniola), que es otro indicio para la azurita (SELDES; BURUCÚA; MAIER, et ál., 1999: s.n.). Gabriela Siracusano, que formaba parte de este grupo, en su tesis El poder de los colores, le dedica un capítulo entero a los "Polvos azules en los Andes", equiparándolos también con azurita. Cita a Joseph de Arriaga, en su obra Extirpacion de la idolatria del Piru, editado en Lima, en el año 1621, quien expone que "Binços son polvos de color azul muy finos" (DE ARRIAGA, 1621: 7). Aunque solamente habla de polvos de color azul, puede suponerse que se refiere a un mineral de cobre de color azul de las minas de la región.

En la Descripción del virreinato del Perú, de comienzos del siglo XVII, hay una "Memoria de todos los géneros de mercadurías que son necesarios para el Perú y sin ellas no pueden pasar; porque no se fabrican en la tierra" y están incluidos "polvos azules finos" (LEWIN, 1958: 132). Bruquetas detectó, en el caso de Lima y a partir del siglo XVII, en los registros de mercadería, que el término polvos azules surge con sorprendente frecuencia. Bruquetas afirma que, hasta ahora, no hay constancia de una producción minera en Atacama y Lípez a escala equiparable a la presencia de este producto en el comercio. Por unos registros de navíos, Bruquetas se inclina a atribuirle una procedencia europea. Las grandes cantidades, el precio indicado, relativamente bajo, y un documento que atestigua su uso para decorar objetos cerámicos, cuestionan que pudiera tratarse de azurita (BRUQUETAS, 2009: 155). Siracusano también comprobó que los polvos azules figuran a menudo entre la mercaderías circulantes en los siglos XVII y XVIII en el área andina (SIRACUSANO, 2005: 113). Según un registro de barco conservado en el Archivo General de Indias, en la sección de Contratación, en 1752 se llevaron desde Sevilla a Buenos Aires "dos mil libras de polvos azules ordinarios" más "trecientas tt.es de polvos azules". Podría corresponder "tt.es" a toneles o barriles, lo que aumentaría aún más la cantidad enviada. Estas cantidades hacen suponer que los polvos azules no solamente pueden haber servido como pigmento, sino para otros usos más comunes.

\begin{tabular}{|c|c|c|c|c|c|c|}
\hline \multicolumn{7}{|c|}{ NOMENCLATURA INDETERMINABLE DE LOS PIGMENTOS SEGÚN LAS FUENTES UTILIZADAS } \\
\hline Fecha & Autor & Fuente & Denominación & Origen & Uso & Pigmento \\
\hline 1632 & $\begin{array}{l}\text { Ley IV, (ver } \\
\text { p. 21) }\end{array}$ & $\begin{array}{l}\text { Tomo quinto de las leyes de recopilación, } \\
\text { que contiene los libros séptimo, i octavo., } \\
\text { Imprenta Real de la Gazeta, Madrid 1776, pp. } \\
206-207\end{array}$ & Polvos azules & - & $\begin{array}{l}\text { Para aderezos } \\
\text { de valonas }\end{array}$ & ? \\
\hline $\begin{array}{l}1653, \\
\text { reeditado } \\
\text { en } 1729\end{array}$ & $\begin{array}{l}\text { González de } \\
\text { Salcedo, P. }\end{array}$ & GONZÁLEZ DE SALCEDO, 1729: 364 & $\begin{array}{l}\text { Polvos azules } \\
\text { de Holanda }\end{array}$ & Holanda & $\begin{array}{l}\text { Se nombra } \\
\text { entre utensilios } \\
\text { para pintores }\end{array}$ & $?$ \\
\hline
\end{tabular}


La bien conocida producción artística en las misiones guaraní-jesuíticas en los siglos XVII y XVIII en la provincia de Paracuaria (actualmente corresponde a la región fronteriza de Paraguay, Argentina y Brasil) fue el tema del arriba mencionado proyecto de investigación (EMMERLING; GRAMATKE, 2019). En éste se investigaron diferentes documentos ligados con estos talleres artísticos en los cuales aparecía el término polvos azules, pero aparentemente aplicado a diferentes pigmentos azules. En los libros de cuentas para el abastecimiento de aquellas misiones muy a menudo figura el término entre otros pigmentos rojos, verdes, amarillos y blancos, generalmente en cantidades de algunas libras. El precio en los años 1730 hasta 1740 varía entre ocho y catorce reales por libra, lo que concuerda con los precios para el polvo azul en Lima, que eran entre dos a catorce reales la libra, mientras que el precio de una libra de azurita en el siglo XVII era mucho más alto, entre veintidós y ciento tres reales (BRUQUETAS, 2009: 155). El término también aparece en nueve de los treinta inventarios de aquellas reducciones, elaborados con motivo de la expulsión de la Orden del Paraguay en 1767. La cantidad de estos polvos inventariados en los diferentes pueblos varía entre las dos libras y aumenta hasta cuatro arrobas y media (BRABO, 1872: 299 y 324). Brabo, que en 1872 transcribió los inventarios, interpretó

Colores para la Reducción guaraní-jesuítica de San Lorenzo: una libra de polvos auzul á 14 reales, fecha 1739, en: 1730 -1745. Misiones. Cuentas con los Pueblos, Colegios y Oficios. Visitas de los Padres Provinciales | fuente AGN, DE/CJ. Sala

XIII 47-3-5, fol. 375r, detalle. Archivo General de la Nación, Buenos Aires

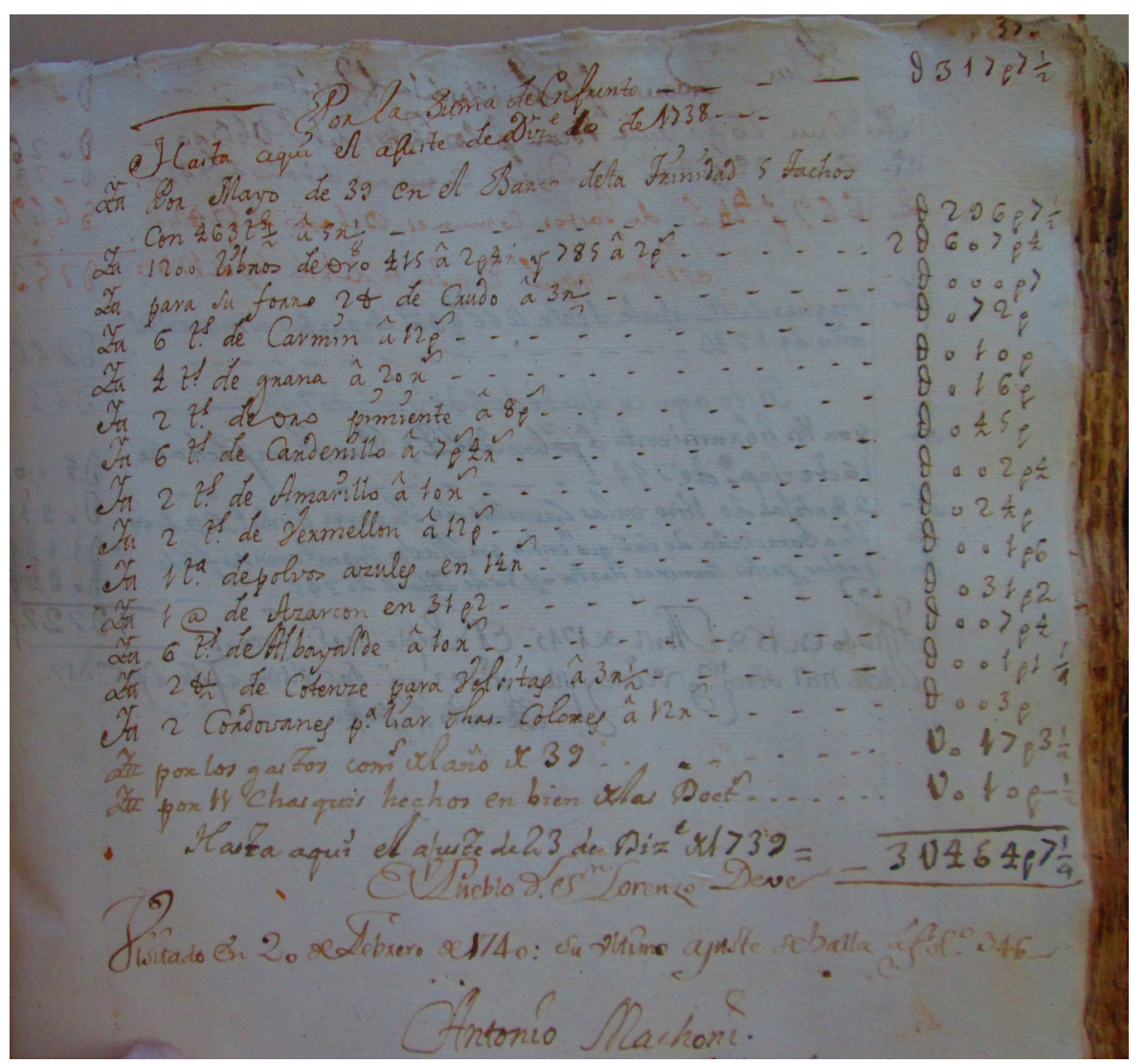


el término como índigo, posiblemente por las cantidades documentadas, que quizá se explicó por servir como tinte para textiles (BRABO, 1872: LXVII). Pero esta interpretación no nos parece convincente, toda vez que en siete de los nueve pueblos en los que se inventariaron polvos azules también se encuentra anotado el añil, en los mismos documentos. En cambio llama la atención que los demás sinónimos comunes de la época de la azurita, anotados por Siracusano (azul de montaña, piedra armenia, azul fino, azul de Santo Domingo, azul de cenizas de Sevilla o cenizas azules (SIRACUSANO, 2005: 111), no aparecen en ningún inventario, y el esmalte solamente figura una sola vez entre los pigmentos inventariados en Trinidad, donde no figura el de polvos azules (BRABO, 1872: 426). José Sánchez Labrador, uno de los misioneros que trabajó durante una década en las misiones guaraníes, en su enciclopedia de 1771 sobre la naturaleza paraguaya, dedica un corto capítulo a los "polvos azules minerales". Anota: "Polvos azules. Piedras azules. En la Hacienda de la Doctrina de San Lorenzo de Indios Guaranis, hay piedras que no son muy duras, y de lo que, ó roban las aguas, ó golpean otras piedras, se ven unos polvos azules, bien finos, y que se pueden emplear en pinturas, molidos exactamente en la piedra de Pintores. No se si estas piedras son como las que hay en Polonia, Alvernia, y otras partes en las Minas de Cobre, a las quales llaman los Naturalistas, Cenizas Azules, por ser polvos de dichas piedras, que tambien son blandas, y estan casi hechas polvo. Muelen con agua las dichas cenizas, ó polvos azules para hacerlos mas finos, y emplearlos en la pintura. No sirve con aceyte, porque se enegrece. Tal vez tienen el color verdoso, y entonces las dicen, Cenizas verdes. Lo cierto es, que suelen dar las Azules un color tan vivo, que no hace falta el Azul ultramarino, ni el Lapiz Lazuli." (SÁNCHEZ LABRADOR, 1771: fol. 95v; GRAMATKE, 2019: 167). No queda nada claro a qué tipo de piedras en la región de las misiones se refiere el jesuita, pero por la alusión a piedras minerales de minas de cobre, el posible tono verdoso y la denominación de cenizas, Sánchez Labrador parece evocar la azurita. En todo caso, su descripción recuerda mucho al párrafo sobre las cenizas azules del diccionario de Bomare (1764), aunque este agrega que las minas de la Auvernia se encuentran en el territorio de Puy de Mur (BOMARE, 1764a: 448). El hecho de que Sánchez Labrador no menciona las minas americanas despierta la sospecha de que solamente copió el texto y no dominaba demasiado esta materia. Esta duda se concreta cuando, más tarde, se confunde nuevamente. Describe que los indígenas en las misiones sabían vidriar loza. Para vidriados azules menciona polvos azules, lo que correspondería al hallazgo documental de Bruquetas, arriba citado. Creemos que pudiera ser el vidrio de cobalto pulverizado lo que utilizaban los guaraníes, pero Sánchez Labrador, presumiblemente por desconocer la materia, no lo aclara (SÁNCHEZ LABRADOR, 1771: fol. 298v). También copia varias recetas de cómo hacer el azul de Prusia, en el sexto método se vale del término "polvo azul", esta vez en singular. Dice que "se precipitará el polvo azul, ó poso", como resultado del proceso de la fabricación descrita (SÁNCHEZ 


\begin{tabular}{|c|c|c|c|c|c|c|}
\hline \multicolumn{7}{|c|}{ NOMENCLATURA DE AZURITA } \\
\hline Fecha & Autor & Fuente & Denominación & Origen & Uso & Pigmento \\
\hline 1659 & Pinelo, L. & SELDES et. ál., 1999: s.n & $\begin{array}{l}\text { blue powder for pain- } \\
\text { ters, blue powder } \\
\text { that was extracted } \\
\text { mainly from Santo } \\
\text { Domingo, Hispaniola }\end{array}$ & $\begin{array}{l}\text { Perú y Santo } \\
\text { Domingo }\end{array}$ & Para pintores & Azurita \\
\hline 1726 & $\begin{array}{l}\text { Real } \\
\text { Academia } \\
\text { Española, } \\
1726\end{array}$ & RAE 1726: 523 & polvos azules & $\begin{array}{l}\text { Minas de plata } \\
\text { y oro }\end{array}$ & - & Azurita \\
\hline 1771 & $\begin{array}{l}\text { Sánchez } \\
\text { Labrador, J. }\end{array}$ & SÁNCHEZ LABRADOR, 1771: fol. 95v & $\begin{array}{l}\text { polvos azules, } \\
\text { piedras azules }\end{array}$ & Paraguay & Pigmento & $\begin{array}{l}\text { Azurita, } \\
\text { presumi- } \\
\text { blemente }\end{array}$ \\
\hline 1788 & $\begin{array}{l}\text { Terreros y } \\
\text { Pando, E. de }\end{array}$ & TERREROS Y PANDO, 1788: 173 & polvos azules & $\begin{array}{l}\text { Mineral del terri- } \\
\text { torio de Macas }\end{array}$ & & $\begin{array}{l}\text { Azurita, } \\
\text { presumi- } \\
\text { blemente }\end{array}$ \\
\hline 1999 & $\begin{array}{l}\text { Siracusano, } \\
\text { G. }\end{array}$ & SIRACUSANO, 2005: 111-116 & polvos azules & Andes & & Azurita \\
\hline 1621 & $\begin{array}{l}\text { Arriaga, } \mathrm{J} . \\
\text { de }\end{array}$ & DE ARRIAGA, 1621: 7 & $\begin{array}{l}\text { Biços son polvos de } \\
\text { color azul muy fino }\end{array}$ & Perú & Ritos indígenas & $\begin{array}{l}\text { Azurita, } \\
\text { presumi- } \\
\text { blemente }\end{array}$ \\
\hline 1764 & $\begin{array}{l}\text { Bomare, J. } \\
\text { C. V. de }\end{array}$ & BOMARE 1764a: 448 & $\begin{array}{l}\text { cendre bleue, pie- } \\
\text { rre bleue, réduite en } \\
\text { poudre }\end{array}$ & $\begin{array}{l}\text { Polonia, } \\
\text { Auvergne }\end{array}$ & Pigmento & $\begin{array}{l}\text { Azurita, } \\
\text { presumi- } \\
\text { blemente }\end{array}$ \\
\hline
\end{tabular}

LABRADOR, 1771: fol. 65v). Otra fuente que menciona polvos azules en el contexto del azul de Prusia es un libro de Aranceles de la aduana española, del año 1785, donde aparece: "Azul de prusia, ó polvos azules, cada libra docientos y catorce maravedis [...]", y queda la duda de si el autor aplica los dos términos como sinónimos o si es algo distinto.

Los diccionarios de la Real Academia Española tampoco disminuyen la confusión. De las ediciones de los siglos XVII hasta XIX, únicamente la de 1726 explica que polvos azules son los que se sacan de las minas de plata y oro (RAE, 1726: 523), lo que indicaría azurita. En 1788, Esteban de Terreros y Pando menciona, en su Diccionario castellano con las voces de ciencias $y$ artes $y$ sus correspondientes en las tres lenguas francesa, latina e italiana [...], los polvos azules como "cierto mineral del territorio de Macas en la América. Viaj. Am." (TERREROS Y PANDO, 1788: 173), lo que nos llevaría a pensar nuevamente en la azurita, considerando las minas de cobre en aquella región ecuatoriana, las que se explotan hasta el día de hoy. Lamentablemente, en esta entrada omitió las voces correspondientes en francés, latín e italiano. Pero la nota bibliográfica de Terreros y Pando remite 
al viaje a la América meridional, de 1735 a 1745, de Jorge Juan y Santacilia y Antonio de Ulloa. En el relato de esta expedición (hoy mejor conocido por la publicación de Barry bajo el título Noticias secretas de América [...]), se mencionan las minas de Macas y los polvos azules, con la intención de la mejora económica de España, pero tampoco queda claro de qué se trata: "En el territorio de Macas, que pertenece á la provincia de Quito, se encuentran minas de polvos azules, bien que estas pertenecen á los payses poblados de infieles. Esto no obstante, los habitadores de aquellas cortas poblaciones españolas que hay allí, se suelen arriesgar à irlos à sacar en algunas ocasiones; y si se poblara aquel pays procurando reducir à los Indios, se podrian cultivar estas minas con formalidad, las quales serian de grande utilidad, pues se ahorrarian las sumas crecidas que sacan los extrangeros de España con lo que traen de este mineral" (BARRY, 1826: 570). Y concluye: "Ya tenemos en nuestras Indias, y sin salir de la provincia de Quito, descubierto el tesoro de dos géneros de especería fina, de los polvos azules y del benjuí, los quales extraen de España porciones no cortas de dinero, porque se compran à los extrangeros de lo que traen del Oriente, no solamente para lo que se consume en España, mas para lo que se gasta en las Indias, y aun en la misma provincia en donde ello se produce [...]" (BARRY, 1826: 579). Efectivamente, en Europa había importaciones del benjuí desde Borneo y Java, y la referencia a un azul traído del Oriente indicaría el lapislázuli, que se importaba desde Afganistán o desde China (BRACHERT, 2001: 37; 150151). Esto también debe haberlo sabido John Adams, el traductor de la obra de Ulloa al inglés en 1806, y equiparó polvos azules con lapislázuli. Traduce: "Among the infinite variety of trees which crowd the woods of this country one of the most remarkable is the storax the gum of which is of a most exquisite fragrancy but is rare the trees growing in places at some distance from the villages and it is dangerous going to them by reason of the savage Indians who lie in wait like wild beasts. The like may be said with regard to the mines of Polvos Azules or Ultra-marine from which by reason of that danger very little is brought but a finer colour cannot be imagined" (DE ULLOA: 1806: 357). El embrollo aumenta con el libro Geografía General para el uso de la Juventud de Venezuela de Feliciano Montenegro Colón de 1834, donde se puede leer que se encuentra "colbato [sic] y polvos azules en Macas...". Queda abierto si utiliza aquí "colbato" (presumiblemente se refiere al cobalto) y polvos azules como sinónimo o algo diferente (MONTENEGRO COLÓN, 1834: 278). El cobalto sería el ingrediente que da color al vidrio de cobalto, pues, el esmalte.

Estos ejemplos documentan que el término polvo azul se utilizaba sin normativa. Los orígenes indicados, como las minas de Atacama, Santo Domingo, Polonia y la Auvernia indicarían azurita; pero los precios señalados en los libros de cuentas contradicen que se trate de azurita, por haber sido mucho más cara en la época. Otras fuentes lo equiparan con ultramarino, por su supuesto origen del Oriente, o lo relacionan con cobalto, que sería el agente 


\section{NOMENCLATURA DE VIDRIO DE COBALTO PULVERIZADO}

\begin{tabular}{|c|c|c|c|}
\hline Fecha & Autor & Fuente & Denominación \\
\hline 1605 & $\begin{array}{l}\text { Patente de producción de } \\
\text { esmalte en Inglaterra }\end{array}$ & HARLEY, 1970: 52 y 183 & Smalt, Smault, washing blue \\
\hline 1679 & Kunckel, J. & KUNCKEL, 1679: 59 & blaue Stärcke, blaue Smalta \\
\hline 1694 & de La Hire, P. & DE LA HIRE 1730: 672-673 & -Azur á poudrer (más grueso), -l’Email (más fino) \\
\hline 1702 & Marperger, P. J. & MARPERGER, 1702: 1196 & $\begin{array}{l}\text { Smalta, Blöhe, Farb zur blauen Stärck, outremer commun o outre- } \\
\text { mer de Hollande }\end{array}$ \\
\hline 1721 & Croeker, M. & CROEKER, 1721: 89 & Öl oder Stärckblau, blau Smalta, Blaustrcklis, Streublau \\
\hline 1726 & Savary des Bruslons, J. & $\begin{array}{l}\text { SAVARY DES BRUSLONS, } \\
\text { 1726: col. } 204\end{array}$ & $\begin{array}{l}\text { azur en poudre ou a poudrer, cendre d'azur, émail, azur en pierre, } \\
\text { Smalte, outremer comun, outremer d'Hollande }\end{array}$ \\
\hline 1726 & Bohn, G. C. & BOHN, 1726: 51-54 & Blaue Schneeberger-Farbe, blauer Amdam \\
\hline $1730-1740$ & $\begin{array}{l}\text { Archivo General de la } \\
\text { Nacion, Buenos Aires, Libro } \\
\text { de cuentas de las reduccio- } \\
\text { nes jesuíticas en Paraguay }\end{array}$ & $\begin{array}{l}\text { AGN, DE/CJ. Sala XIII- } \\
\text { 47.3.5: fol. } 214 \text { y } 203\end{array}$ & polvos azules \\
\hline 1741 & $\begin{array}{l}\text { Archivo Histórico Nacional, } \\
\text { Madrid, Cédula real } 1741\end{array}$ & $\begin{array}{l}\text { AHN, Madrid, Consejos- } \\
\text { Juros, } 544, \text { N. } 31\end{array}$ & polvos azules \\
\hline 1741 & $\begin{array}{l}\text { Ludovici, C. G. (trad. de } \\
\text { Savary des Bruslons) }\end{array}$ & $\begin{array}{l}\text { LUDOVICI, 1741, col. } \\
\text { 576- } 577\end{array}$ & Smalte \\
\hline 1743 & Chomel, N. & CHOMEL, 1743 : col. 231 & azur de Hollande, l'émail que se prepara en Amsterdam \\
\hline 1758 & $\begin{array}{l}\text { Postlethwayt, M. (trad. de } \\
\text { Savary al inglés) }\end{array}$ & POSTLETHWAYT, 1757: 295 & smalt, Dutch azure, starch with smalt \\
\hline 1775 & Bowles, G. & BOWLES, 1775: 398 & esmalte \\
\hline 1775 & Krünitz, J. G. & KRÜNITZ, 1775: 614 & Blaue Stärke \\
\hline 1780 & Suárez, M. J. & SUÁREZ, 1780: 271-277 & polvos azules \\
\hline 1781 & Jacobsson, J. K. G. & JACOBSSON, 1781: 223 & Blausel, Holländisch Blau; Smalte \\
\hline 1788 & Larruga, E. & LARRUGA, 1788, 172-174 & polvos azules \\
\hline 1788 & Suárez, M. J. & SUÁREZ, 1778: 247 y 258 & azul de almidón, esmalte azul o azul de esmalte \\
\hline 1789 & Schedel, J. C. & SCHEDEL, 1789: 111-115 & Blaue Farbe, blaue sächsische Farbe, Smalte \\
\hline 1792 & Beckmann , J. & BECKMANN, 1792: 202- 203 & Schmalte = Glas, gemahlen: blaue Farbe, Eschel oder Stärcke \\
\hline 1796 & Chaptal, J.-A. (ed. española) & CHAP TAL 1796: 135 & polvos azules (poudre bleu) \\
\hline 1797 & Nemnich, P. A. & NEMNICH, 1797: 319 & Polvos azules, en alemán: Blaussel \\
\hline 1797 & Nemnich, P. A. & NEMNICH, 1797: 438 & $\begin{array}{l}\text { Blaussel: en español: polvos azules, en inglés: powder blue o starch } \\
\text { blue, en francés: bleu d'azur, bleu d'empois }\end{array}$ \\
\hline 1797 & Nemnich, P. A. & NEMNICH, 1797: 287 & $\begin{array}{l}\text { Azul de esmalte, azul de azur. Smalte; Blaussel; Azul de piedra; } \\
\text { Azul de tierra; Azul cenizas o cenizas azules }\end{array}$ \\
\hline
\end{tabular}


Origen

Inglaterra, Holanda

Alemania

Alemania

Alemania

Alemania, Holanda

Alemania y Bohemia

color

en conjunto con otros pigmentos

esmalte

importación del extranjero

Alemania

Amsterdam, otras partes de las

Provincias unidas

azulete (nocivo para la ropa y para el ser humano)

esmalte

Holanda

Alemania

Alemania

Alemania

Alemania (SUÁREZ, 1778: 247)

Alemania, Europa

Alemania

$-$

for painters, decorators, potters, paper-maker, paper-marblers; laundresses

esmalte

esmalte

esmalte

esmalte

esmalte

esmalte

esmalte

para esmaltar las vajillas de porcelana. Resistencia a la intemperie

esmalte

mejor como azulete que para la pintura

esmalte

pigmento, azulete

esmalte

fábricas de loza y porcelana de Europa, además para esmaltar, para pintar al fresco, para realzar la blancura de las telas de lino

esmalte

confiteros. Perjudicial para la salud

esmalte

fábricas de loza y otros usos

esmalte

para azulete; para pintores

esmalte

esmalte

azulete

esmalte

las lavanderas y blanqueadores) y el esmalte az

pintores)

como pigmento, azulete, insecticida

esmalte

pigmento, azulete, (venenoso)

esmalte

para pintar al fresco, sobre barro, porcelana, para teñir vidrio, para confiteros, como polvo

de carta 


\begin{tabular}{|c|c|c|c|}
\hline 1797 & Nemnich, P. A. & NEMNICH, 1797: 299 & $\begin{array}{l}\text { Esmalte; Esmalte azul, o de colores, o vidrio en pasta o molido. } \\
\text { Schmelz, Email }\end{array}$ \\
\hline 1810 & Mortimer, T. & $\begin{array}{l}\text { MORTIMER, 1810: entrada } \\
\text { "Powder-Blue" }\end{array}$ & $\begin{array}{l}\text { Powder-blue or starch-blue. alemán: Blaussel, francés: bleu e’em- } \\
\text { pois, español: polvos azules }\end{array}$ \\
\hline 1814 & Schedel, J. C. & SCHEDEL 1814: 135-137 & $\begin{array}{l}\text { Blaue Farbe, blaue Kobaltfarbe, blaue Smalte, fr. le smalte, Bleu } \\
\text { d'azur, engl. Smals, Pouder blue, span. Polvos azules }\end{array}$ \\
\hline 1858 & De Galdo, M. M. J. & DE GALDO, 1858: 287 & $\begin{array}{l}\text { polvos azules de diferente finura; estos polvos son los que se lla- } \\
\text { man esmalte }\end{array}$ \\
\hline 1752 & $\begin{array}{l}\text { Archivo General de la } \\
\text { Nación, Buenos Aires }\end{array}$ & $\begin{array}{l}\text { Contratación,1711, N. 2, fol. } \\
\text { 402r; Contratación,1711, N. } \\
\text { 2, fol. } 412 \text { r }\end{array}$ & polvos azules \\
\hline 1834 & Montenegro Colón & $\begin{array}{l}\text { MONTENEGRO COLÓN, } \\
\text { 1834: } 278\end{array}$ & colbato [sic] y polvos azules \\
\hline $1701-1704$ & $\begin{array}{l}\text { Libro de Reales Alcabalas, } \\
\text { de } 1701-1704\end{array}$ & SIRACUSANO, 2005: 113 & polvos azules \\
\hline siglo XVII & Lewin, B. & LEWIN, 1958: 132 & polvos azules \\
\hline siglo XVII & Bruquetas, R. & BRUQUETAS, 2009: 155 & polvos azules \\
\hline
\end{tabular}

colorante del pigmento esmalte. Si el término en el documento citado de los aranceles se utilizó como sinónimo de azul de Prusia está aún por confirmar. Pero lo que se puede constatar es que los polvos azules hasta ahora, más que nada, aparecen en documentos ligados con los virreinatos españoles en las Américas; Bruquetas en sus investigaciones sobre la pintura española en los Siglos de Oro no menciona este término (BRUQUETAS, 2010); el vocablo aparece principalmente en el ámbito del comercio, muchas veces en grandes cantidades y también en conexión con vidriar loza, lo que inspira la orientación de esta investigación.

\section{POLVOS AZULES EN LA LITERATURA TÉCNICA. SINÓNIMO PARA EL VIDRIO DE COBALTO PULVERIZADO}

Un hallazgo en el Archivo Histórico Nacional en Madrid dio la pista para poder identificar los polvos azules con vidrio de cobalto molido, y para abrir el abanico de sus usos, más allá de la pintura y el vidriado. Se trata de una cédula real de 1741 en el contexto de la difícil situación económica de España. A principios del siglo XVIII, la industria española era casi inexistente 
y el balance comercial muy desfavorable, con una fuerte competencia exterior y una gran salida de capital. Para paliar esta situación, la nueva dinastía borbónica intentó estimular el desarrollo de las actividades artesanales y comerciales creando fábricas de manufacturas reales según el modelo francés y favoreciendo la iniciativa privada a través de privilegios fiscales. Uno de estos favorecidos fue Diego de Egan, de nacionalidad irlandesa. Por la cédula real de 1741, con la que se otorgó la licencia a Egan para montar su fábrica de añil afinado en Madrid, sabemos que este añil debía suplir a los polvos azules, que se solían utilizar "para lustrar la ropa y darles el color de perla" y que el añil afinado sería mucho más económico que los polvos azules, los que había que comprar traídos del extranjero a precios muy altos. Otra ventaja que llevaría el añil afinado sobre los polvos azules era que este no era nocivo para la salud y no gastaba la ropa como sí lo eran los polvos azules (ver pp. 83-84). Aquí entran los tratados técnicos de la ilustración, que son memorias sobre la producción de materiales, fábricas y el comercio de la época. Surgen en los diversos países europeos y se tradujeron de una lengua a otra, aumentados y adaptados a las necesidades específicas del país destinatario. Sabemos, por ejemplo, por Eugenio Larruga (1747-1803), economista y escritor ilustrado español, quien le dedica un capítulo com- 
pleto a los esfuerzos del irlandés de la cédula real mencionada arriba, en su obra Memorias políticas y económicas sobre los frutos, comercio, fábricas y minas de España, que Egan fracasó en su empeño de instalar la fábrica para elaborar el sustituto del polvo azul importado (LARRUGA, 1788, 172-174).

La información brindada por la cédula real sugiere que aquí el término polvos azules apunta hacia el esmalte, por las siguientes razones. Primero, el esmalte fue importado en España en aquella época desde los Países Bajos e Italia (BRUQUETAS, 2002: 173), Inglaterra (HARLEY, 1970: 51-53) y Alemania (BECKMANN, 1792). Segundo, en su libro Beyträge zur Geschichte der Erfindungen de 1792, Beckmann (1739-1811, naturalista, economista y autor prolijo) trata el vidrio de cobalto, su pulverización y los resultantes de varias cualidades, y escribe que la suerte barata servía para darle visos azules a la ropa blanca (BECKMANN, 1792: 203). Tercero, lo venenoso y nocivo para la ropa y la salud lo confirma Beckmann (BECKMANN, 1792: 203) refiriéndose al contenido de arsénico y bismuto, explicado por Harley (HARLEY, 1970: 51). Además Beckman menciona otros usos del vidrio de cobalto pulverizado, como pigmento para pintores, para la pintura de porcelana y esmalte de loza (BECKMANN, 1792: 202-203).

Aunque los grandes yacimientos de cobalto en Alemania, sobre todo en la región de Sajonia, se conocen desde 1470, las primeras fábricas de esmalte se establecieron en Holanda, país que no poseía minas de cobalto en su territorio. Adquirían el safre de Sajonia y lo convertían en esmalte, lo que resultó un floreciente negocio (HAMMER, 2004: 114). La primera fábrica en Sajonia no se construyó hasta 1635, pero el negocio para el consumo nacional e internacional fue tan rentable que el príncipe electo de Sajonia tomó posesión exclusiva del comercio del cobalto y prohibió estrictamente la exportación privada (HAMMER, 2004: 108).

Sorprendentemente, España disponía de una de las minas de cobalto más grandes, pero esta había sido aprovechada durante mucho tiempo por los alemanes. Bowles, un ingeniero de minas irlandés, que perteneció al selecto grupo de especialistas y técnicos extranjeros captados por Antonio de Ulloa durante su viaje de espionaje industrial a comienzos de la década de los cincuenta por Francia, Centroeuropa y Escandinavia, con vistas a contribuir al desarrollo tecnológico y científico español, y para formar expertos españoles (SÁNCHEZ ESPINOSA, 2002: 255), explica que esta mina en las inmediaciones de Pan, Valle de Gystau en los Pirineos de Aragón, fue explotada por los alemanes a causa del desconocimiento en la materia por parte de los españoles (BOWLES, 1775: 339). Según él la calidad del cobalto era mucho mejor que el de Sajonia: "tan purgado de materias estrañas, y tan rico de la tierra colorante azul, que embebía tres ó quatro veces mas arena ó Quarzo que el de Saxonia." (BOWLES, 1775: 403). Sin emplear el término polvos azules, describe que el "Safre se pone en un horno bien encendido con los 
fuelles, se derrite y forma una piedra azul, que se llama esmalte: y reducido este esmalte á polvo mui fino, es el hermoso color azul que se admira en la Porcelana" (BOWLES, 1775: 403). Según Bowles, eran las factorías de Schneeberg, en Sajonia, las que se aprovechaban de este cobalto para fabricar el esmalte y lo vendían a todas las fábricas de loza y porcelana de Europa, además para esmaltar, para pintar al fresco, para realzar la blancura de las telas de lino (lo que confirma nuevamente la interpretación del término en la cédula real de 1741), y para "otros mil usos" (BOWLES, 1775: 398).

Ya en 1676 se había creado la Real Junta de Comercio y Moneda con la pretensión de reactivar la deprimida economía española. Uno de sus objetivos era promover la publicación de obras que fomentaran la industria y el comercio. Impulsó la traducción de tratados técnicos y científicos extranjeros (BRUQUETAS, 2010: 76). Uno de los proyectos más interesantes en relación con los polvos azules fue la publicación de las Memorias instructivas, útiles y curiosas... de Miguel Jerónimo Suárez, archivero de la Real Sociedad Económica de Amigos del País de Madrid. En la Memoria XXVI, Suárez se basa en los textos de Kunckel y en el Memorial de Zimmermann sobre la producción del esmalte según la práctica en Sajonia (SUÁREZ, 1778: 247-260, aquí 257), indicando su uso para pintar la loza y colorear vidrio, y emplea los términos azul de almidón (que sirve para las lavanderas y blanqueadores) y el esmalte azul o azul de esmalte (que sirve para los pintores) (SUÁREZ, 1778: 258). El término polvos azules lo utiliza en otro capítulo titulado "Modo de preparar el safre que haya de emplearse en colores en el Arte de Vidriería" (SUÁREZ, 1780: 271-277), refiriéndose nuevamente a Kunckel y a la producción en Schneeberg y Misnia, en Alemania. Dice: "El Safre se gasta en las Reales Fábricas de San Ildefonso, bajo el nombre de polvos azules, y cuesta de cinco á seis reales de vellon la libra. Asi el safre como el arsénico, y minio se traen de fuera del reyno, y aunque el consumo en dicha Manufactura no es considerable, lo es, sin embargo, el mucho que se consume en las Fábricas de Loza, y otros usos. Ya se ha visto en la explicación que hace Kunckel del safre, que éste no es otra cosa que la mina del cobalto preparada, y de la cual se saca tambien el arsénico". (SUÁREZ 1780: 277).

Para atajar la salida de las materias primas y luego depender de la importación del producto, Valladares de Sotomayor, otro intelectual ilustrado, utilizando el ejemplo del cobalto, pide, en 1788, crear "una Secretaría universal, cuya cabeza no debería tener otro cuidado, que el de la expedición de todos los encargos pertenecientes al comercio interior del reyno: los de la propagación de los simples, y sus seguridades: los de todo género de minerales (porque hay algunos que producen á los extrangeros sin noticia nuestras muchas utilidades, y señaladamente el de la piedra zafre, ó cobol, que los Alemanes la llevan atravesando la Francia desde la mon- 
taña de Liera, en el Obispado de Barbastro, reyno de Aragon, al estado de Witembert, donde á beneficio de la vitrificacion, sacan de ella los polvos azules, que llaman de esmalte, que los Holandeses distribuyen en todo el universo con imponderable utilidad, haciéndose árbitros de este comercio, con desdoro de nuestra nacion)" (VALLADARES DE SOTOMAYOR, 1788: 144). Este espíritu ilustrado también hizo aflorar instituciones científicas para promover los conocimientos naturalistas, tanto en el campo académico (las Reales Academias) como en el práctico (Real Gabinete de Historia Natural, Real Laboratorio de Química de Segovia).

En 1803 se publica en castellano Élémens de Chymie, de Chaptal, que ofrece una descripción científica de la producción del esmalte y también menciona la mina española de los Pirineos. El traductor utiliza el término polvos azules para la denominación francesa "poudre bleu" (CHAPTAL, 1796: 213) y en lo que concierne al uso de los esmaltes explica que "sirven para dar el aparejo á los lienzos batistas, lino, muselina, hilos, \&c. El azul se mezcla con el almidón para hacer lo que llaman empegue, cuyos usos son tan conocidos para preparar el lienzo blanco. También se emplea el azul para pintar sobre el barro, porcelana, y otros; se dá también el color azul a los cristales, saleros, y otros vidrios. También se usa para la pintura al fresco." $Y$ añade "El azul mas basto sirve para los Confiteros, y Alfareros. En Alemania se usa también como polvos de carta" (CHAPTAL, 1803: 135).

Aunque sorprende por su citada venenosidad, se confirma, entre otros autores, como en De Galdo en 1858, que también escribe con el espíritu de mejorar la economía española: "El más fino se usa en el aderezo de los lienzos, batistas, linos y muselinas; el de segundo grado, sirve para teñir el engrudo que se emplea en la pintura en esmalte; el más grueso sirve á los confiteros y á los pintores de casas para hacer fondos azules" (DE GALDO, 1858: 287).

Esta información sobre los usos variados del esmalte, que se repite en los tratados técnicos españoles de la llustración, explica las grandes cantidades encontradas en el comercio. Dato que se confirma en los diccionarios económicos del siglo XVIII, que veremos a continuación.

\section{LOS POLVOS AZULES EN LOS DICCIONARIOS ECONÓMICOS DEL SIGLO XVIII}

Otro género literario, que se propaga en el siglo XVIII en Europa, y que creemos aún no se ha aprovechado debidamente en el ámbito de la investigación de materiales artísticos, son los diccionarios económicos, o de comercio, que informan a los comerciantes sobre la fabricación de las diferentes mercancías y artículos, sus cualidades y posibles falsificaciones. Además de la información suministrada sobre los materiales, permiten ver la terminología 


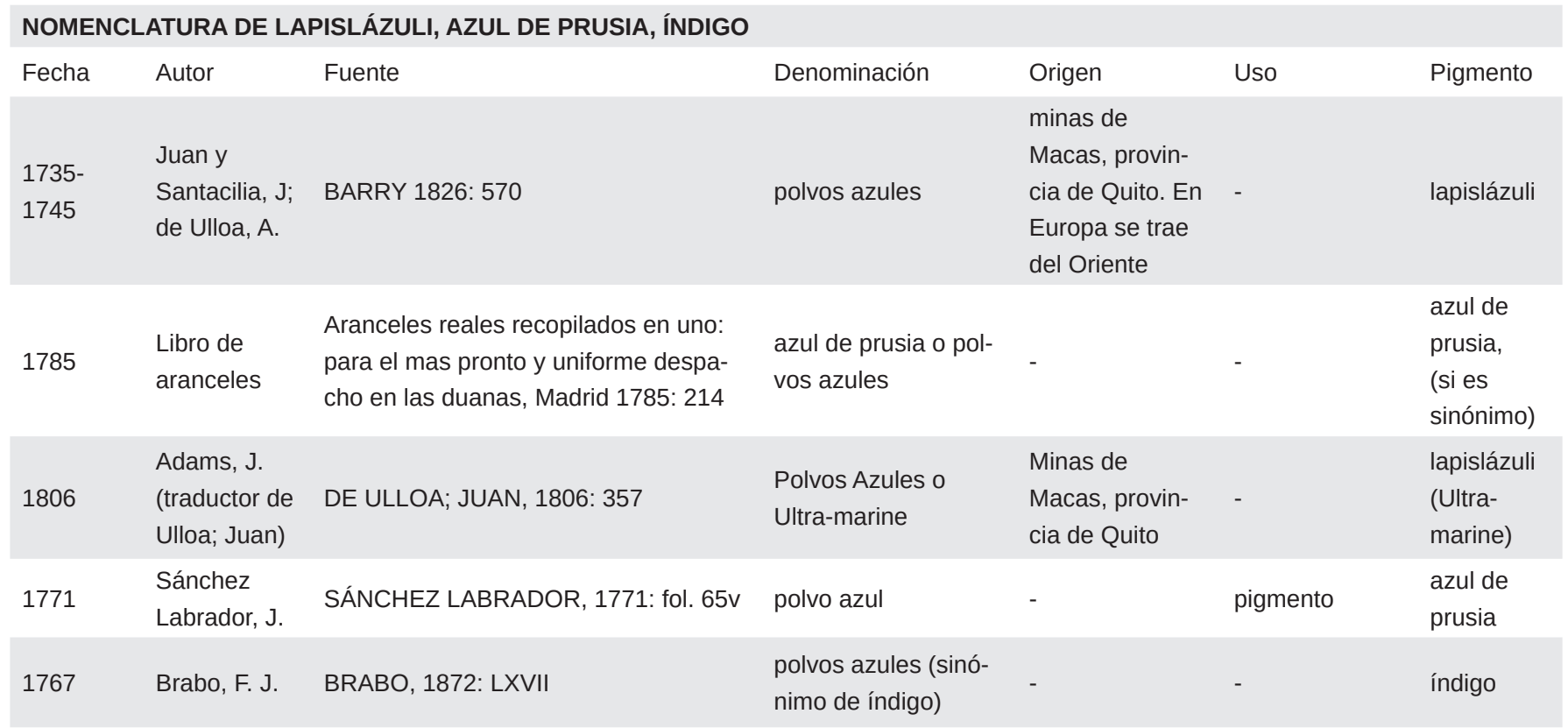

en las diferentes lenguas, lo que puede ayudar a entender por qué un término específico se estableció en el comercio y no forzosamente en los ámbitos del uso del material, como en el caso del esmalte.

Una de las obras más tempranas de este género en Alemania es Das in Natur- und Kunst-Sachen Neu-eröffnete Kauffmanns-Magazin, de Paul Jacob Marperger (1656-1730), publicado en 1702. Marperger explica brevemente el proceso de fabricación del esmalte, qué calidad hay que seleccionar y señala que estaba prohibido exportar el cobalto de la región, para impedir la competencia comercial con el esmalte. Agrega que en Francia el esmalte se llamaría ultramarino común o ultramarino de Holanda (outremer commun o outremer de Hollande) (MARPERGER, 1702: 1196), terminología confirmada más tarde por Savary des Bruslons (SAVARY DES BRUSLONS, 1726: col. 204), cuyo Dictionnaire universel du commerce, en tres tomos, (primera edición en 1723), era el más conocido en Europa. Esta obra fue traducida al alemán y al inglés, pero, como era común en aquella época, con grandes ampliaciones y adaptaciones a las necesidades de cada país. Según Ludovici, quien tradujo a Savary al alemán, el esmalte se empaquetaba en pequeños barriles y se exportó en "inmensas cantidades" a Holanda, Inglaterra, Portugal y muchos otros sitios. Elogia su resistencia a la intemperie, la lluvia y el sol, y que aguanta el fuego. Menciona su uso para esmaltar las vajillas de porcelana (LUDOVICI, 1741, col. 576- 577). Luego explica la organización de las fábricas de esmalte en Sajonia, las denominaciones de las diferentes calidades (que consistían en el variado grosor del grano y la intensidad cromática) y que se exportaba por toda Europa (LUDOVICI, 
Extracto de BOHN; NORRMANN 1805, pag. 178, concerniente a las cualidades, las marcas y el nombre de cada cualidad
1741, col. 577-579). Ya Bohn, en su Des wohlerfahrnen Kaufmanns Anderer Theil, oder Neu-eröffnetes Waaren-Lager, de 1726, describe detalladamente la comercialización en toneles del esmalte producido en Sajonia y Bohemia, el surtido y las denominaciones diversas según la calidad (BOHN, 1726: 51-54), confirmado por Zimmermann (ZIMMERMANN, 1752: 600). Schedel (1748-1803) especifica en su diccionario de comercio que los barriles eran de tres, de dos, de uno o de medio quintal (SCHEDEL, 1789: 112). La repetida información sobre estos toneles lleva a interpretar que la abreviatura "ttes" del registro de barco arriba citado podría corresponder al término tonel. También el Diccionario de la Real Academia Española del año 1739 evoca la relación de tonel con el término alemán "Tonne" (RAE, 1739: 296). La explicación de las marcas con letras en los toneles que indican las diferentes calidades se da en varios libros y diccionarios de comercio; la más exhaustiva es la de Bohn y Norrmann (ver tabla debajo). Suárez traduce algunas de ellas al español: "Embarrilado ya el color, y cerrados los barriles, los ponen la marca, y el nombre con un hierro hecho asqua, y con un lapiz colorado indican la especie que contienen. O.C. quiere decir, ordinario claro : O.H. azul vivo ordinario : M.C. claro de enmedio : M.H. azul vivo de enmedio : G.C ò F.C. un color fino, ò bueno : F.F.C. color fino, y claro, \&c." (SUÁREZ, 1778:

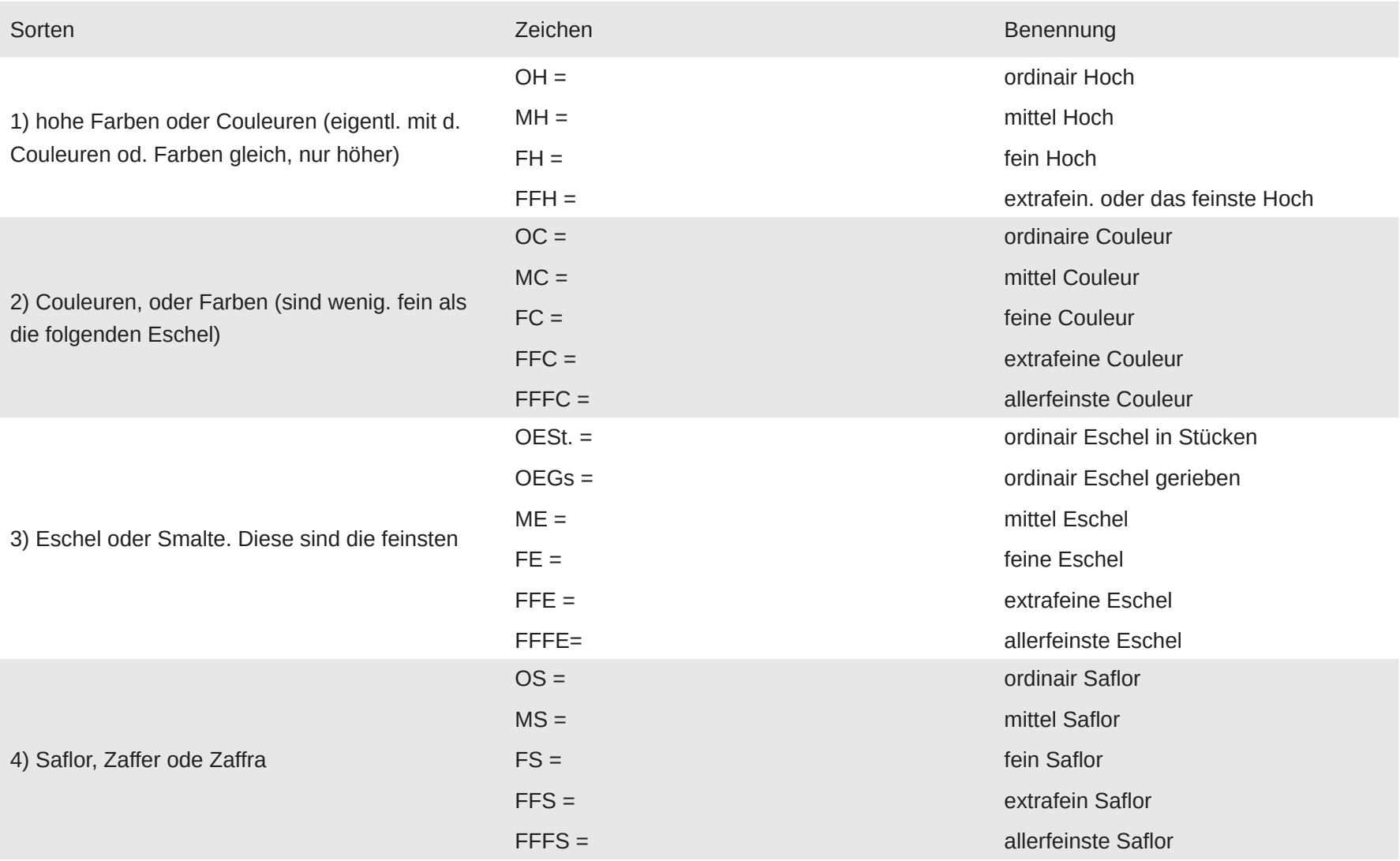


257). En cuanto a la terminología, destacamos que Savary des Bruslons, en su Dictionnaire universel du commerce, explica que el "azur en poudre ou a poudrer" (azul en polvo o para espolvorear) es esmalte pulverizado que se obtenía sobre todo en Alemania y Holanda. El de Holanda era más caro y más estimado porque se parecía mucho al color del lapislázuli, de ahí le vino también el ya mencionado nombre de ultramarino común o ultramarino de Holanda (SAVARY DES BRUSLONS, 1726: col. 204). Luego declara en la entrada "Empois" que hay dos tipos para almidonar la ropa, el blanco, que lleva solamente almidón, y el azul, que lleva el "bleu ou émail de Hollande" (SAVARY DES BRUSLONS, 1726: col. 1801). Aun está por hacer el estudio filológico de todas las denominaciones diferentes del vidrio de cobalto pulverizado y sus correspondientes aplicaciones.

En 1797, Philipp Andreas Nemnich publica un diccionario con los nombres de las mercaderías de la época en doce lenguas, incluido el español, donde aparece literalmente polvos azules. Es de notar que Nemnich hace una diferencia entre esmalte y polvos azules, lo que explicaría por qué entre los pintores de España no aparece el término polvos azules. Lo primero designaría el "esmalte azul, ó de colores, ó vidrios en pasta ó molido" (NEMNICH, 1797: 299). Los polvos azules, según él, serían el "powder blue" o "starch blue", los que se utilizaban para almidonar y darle el viso azul a la ropa. Diccionarios de comercio que se publicaron después, como se puede ver en Mortimer (1730-1810) (MORTIMER, 1810: entrada "Powder-Blue"), y en las reediciones de Bohn y Schedel, se basan en su terminología, y utilizan el vocablo polvos azules para el azulete (BOHN; NORMANN, 1805: 176 y Schedel, 1814: 135). Llama la atención que "powder-blue" y "azur en poudre" son la traducción literal de los polvos azules.

Creemos que aquí podría radicar la confusión de términos, ya que polvos azules, según Nemnich, era únicamente el azulete; y en el comercio, y sobre todo en el de las Américas, se produjo este solapamiento para los demás usos, que ahora se explican.

\section{LOS "MIL USOS" DE POLVOS AZULES EN LAS FUENTES ESCRITAS}

\section{Pigmento}

Hoy en día lo más conocido es el uso como pigmento en la pintura o en las policromías. En España se documenta desde mediados del siglo XV, generalizándose en los dos siglos siguientes, para el fresco y el óleo, importado de Flandes e Italia (BRUQUETAS, 2002: 173-175). Para el óleo el esmalte muestra algunos inconvenientes. De La Hire, en su Traité de la pratique de la peinture de 1694, explica que el esmalte para la pintura se conseguía en dos calidades, que se diferenciaban por el grosor del grano y la profundi- 
dad de tono. A ambos los presenta más aptos para la pintura al temple y el fresco, porque con la técnica al óleo el grano grueso se mezclaba mal y el fino se ennegrecía (DE LA HIRE, 1730: 672-673). Pero, como era mucho más barato que el lapislázuli o la azurita, se volvió muy frecuente en la pintura española del siglo XVII (BRUQUETAS, 2002: 174).

En los tratados españoles de pintura de Vicente Carducho, Francisco Pacheco o Antonio Palomino, se describe bien el uso del esmalte pero no se encuentra la denominación polvos azules (GRAMATKE, 2010: 214 y siguientes). Además, se utilizó como secante para el óleo (GRAMATKE, 2010: 277). En el siglo XVIII el tratadista alemán Croeker le dedica, en su tratado de pintura de 1721, un capítulo entero. Escribe que aunque las mujeres lo utilizan para almidonar la ropa, los pintores no desprecian nada este pigmento. Como se oscurece con el óleo hay que mezclarlo con un poco de albayalde. Croeker también describe la técnica sin pincel, cómo se espolvorea sobre superficies impregnadas con el aglutinante (CROEKER, 1721: 89-90). Esta técnica de espolvorear también la describe de La Hire (DE LA HIRE, 1730: 673) utilizando la misma denominación de "azur a poudrer" que coincide con la arriba mencionada de Savary.

Es interesante hacer notar que estos polvos azules de Holanda también surgen en unas pragmáticas sobre el contrabando en España, editadas en 1653 y reeditadas en 1729. En la "Relación de géneros y mecaderías de Olanda" había, entre otras cosas: "Todo genero de colores para Pintores, y polvos azules. Pinzeles, y brochas" (GONZÁLEZ DE SALCEDO, 1729: 364). Llama la atención que se realcen estos polvos. Quizás el autor se refiere a un uso más amplio que el que se daba a los pigmentos en común. Por su composición y estabilidad se ofrecía también para "pintores de casas para hacer fondos azules" (DE GALDO, 1858: 287), lo que puede explicar la aparición de grandes cantidades en el mercado. Cien años antes Ludovici ya elogia su resistencia a la intemperie, lo que da a entender su uso en superficies exteriores (LUDOVICI, 1741, col. 576- 577).

\section{Colorante de vidrio y esmaltado}

Siendo materia de vidrio, es evidente que el esmalte sirvió para vidriar y pintar porcelana o locería y para elaborar esmaltados (BOHN; NORRMANN, 1805: 177). Si se considera la extendida moda de las porcelanas chinas y la porcelana y locería europea de la época, esto explicaría las grandes necesidades del esmalte. Además, grandes cantidades de este azul se exportaron con la Compañía de las Indias Occidentales a China y Japón, para la pintura de porcelana (SCHEDEL, 1789: 115). Bomare confirma que los chinos utilizaban el "outremer comun", que era lo mismo que el "azur d'Hollande", para la pintura sobre porcelana, pero juzga que el lapislázuli, que utilizaban antes, daba un azul más bello (BOMARE, 1764a: 231). 
El uso de polvos azules para el vidriado lo describe también Sánchez Labrador, pero parece que él es víctima del vocablo genérico de polvos. Escribe que para vidriar locería de color azul "hacese con solos polvos, que comunmente llaman Azules. Muelense un poco, no demasiado, porque perderian el color, y quedarian como tierra. Pintase la pieza con pincel." Hasta aquí podría corresponder al esmalte, pero el autor sigue: "Dexamos dicho en su lugar, en que parte del Paraguay se hallaban Polvos azules" (SÁNCHEZ LABRADOR, 1771: fol. 298v). No obstante, en este parágrafo referido por el autor, que sigue a Bomare, parece que se refiere a la azurita y no al esmalte. La posible utilización de la azurita para vidriado aún está por investigar. Bomare explica que la azurita al calcinarse se vitrifica, pero pierde el color (BOMARE, 1764b: 278). De hecho, por encima de 200 grados celsius, ésta se descompone y Macquer, en su Dictionnaire de Chymie, escribe que el esmalte sería el único azul que se puede utilizar en la vitrificación (MACQUER, 1764: 270).

Sánchez Labrador también describe el cobalto y la manufacturación del esmalte, pero sin utilizar el término polvos azules: "[...] se vitrifica muy facilmente, y entonces dá un bello vidrio Azul, llamado en el Comercio, Esmalte, y Azul de esmalte, ó vidrio de cobalto. Sirve mucho en las pinturas de la Porcelana, y Loza, y en las tincturas de los esmaltes" (SÁNCHEZ LABRADOR, 1771: fol. 161v).

\section{Azulete}

Otro amplio uso se dio en la producción textilera y en el lavado doméstico, para dar visos azules a la ropa, añadiéndolo al agua de lavar y al almidón, tema bien investigado por Delamare (DELAMARE, 2013: 89-93). Son numerosos los libros que mencionan al esmalte para este fin. Se convirtió en materia importante cuando se pusieron de moda las golillas, lechuguillas y cofias confeccionadas de lino fino. Estas telas se almidonaban y con la ayuda de calor (tenacillas especiales o plancha) se compusieron en la forma buscada. Para que guardaran su blanco fresco se añadía un poco de pigmento azul al lavado y al almidón, para ahogar el amarillento natural. Por falta de documentos carecemos de información sobre el lavado doméstico de la época (DELAMARE, 2013: 89-93). En este contexto resulta reveladora la ley sobre los cuellos en España, del año 1632, que restringe bajo pena el uso de lechuguillas prominentes (LEYES, 1776: 206-207). En la pragmática se especifica que a partir de ahora se "lleven valonas llanas, sin invencion... ni aderezadas con goma, polvos azules, ni de otro color" (ver cuadro al margen). Lamentablemente el texto no revela qué tipo de goma se utilizaba o qué se entendía por polvos azules, si podía ser esmalte o índigo. Ni qué decir tiene que la entrada "aderezo" es menos reveladora en el Diccionario de la Real Academia Española, de 1770; allí se lee: "En las telas de seda, y lienzos, es la goma ù otros ingredientes que les echan, para que parez-
Tomo quinto de las leyes de recopilación, que contiene los libros séptimo, i octavo. Madrid: Imprenta Real de la Gazeta, 1776, pp. 206207.

Lei IV.

Mandase traer balonas llanas sin guarnicion, ni aderezo, i prohibese el uso de los cuellos, si no fueren de á dozavo, en la forma, o modo que se contiene en esta lei.

D. Phelipe II. en Madrid año de 1568. en quanto à cuellos, i Don Phelipe IV. en Madrid, en los capitulos de reformacion de la Pragmàtica de 10. de Febrero del año de 1623. cap. 14. lo que toca à balonas, i lo que añade en cuellos.

Mandamos que todas, i qualesquiera personas de qualquier estado, calidad ò condicion que sean, ayan de traer, i traigan balonas llanas, i sin invencion, puntas, cortados, deshilados, ni otro genero de guarnicion, ni aderezadas con goma, polvos azules, ni de otro color, ni con yerro; pero bien permitimos que lleven almidon, i caso que alguno aya de traer cuellos, mandamos que sea del ancho de dozavo, o la lechuguilla de hasta ocho anchos, i no mas, sin genero alguno de hierro, guarnicion, almidon, polvos, ni otro, ni con mas que una tela, no abierto con molde, ni otro instrumento, i los puños ayan de ser de tres anchos, i mitad del dozavo, i con las mismas calidades, (pág. 207) i las lechuguillas, i puños de mugeres se podràn usar como hasta aqui, con tal, que no lleven puntas, ni otra guarnicion mas que un deshilado, como tampoco las han de poder llevar en las balonas, tocas, bueltas, ni en otro trage, ò adorno, ni aderezdadas con polvos azules, ni aforadas con telas de otro color, só pena de perdimiento de los trages, en que se contraviniere á ella, i de cincuenta mil maravedis, aplicados por tercias partes, Camara, Juez, i denunciador: lo qual mandamos assi se guarde, i execute en esta Corte desde el primer dia del mes de Marzo de este año, i en las demàs partes, i Lugares del Reino, dentro de dos meses de la promulgacion desta lei: i prohibimos que ningun hombre, ni muger no pueda ser abrido de cuellos de hombre, ni muger, sò pena de vergüenza pública, i destierro de esta Corte, ò Lugar, donde se contraviniere à este lei. 
can mejor. Gummis, vel alius sussuc pliendis telis inserviens" (RAE, 1770: 70). En la literatura centroeuropea se puede leer que para el lino se usaba generalmente el esmalte. Por ejemplo, cuando en 1605, en Inglaterra, se pedía el monopolio de la patente para la manufactura del esmalte, se menciona la suerte pálida del pigmento (blue starch) utilizada para azular textiles (HARLEY, 1970: 52 y 183). Y a partir de esta fecha el uso de esmalte mezclado con almidón aparece en numerosos tratados europeos (DELAMARE, 2013: 91). Kunckel lo nombra, en 1679, en su Ars vitraria experimentalis, justificando que en Sajonia no se vendía el cobalto puro, sino solamente mezclado con arena, para impedir la producción del azulete en el extranjero (KUNCKEL, 1679: 59).

Philippe de La Hire, en 1694, en su ya citado Traité de la pratique de la peinture, explica las dificultades del esmalte para la pintura y que se prestaba muy bien para mezclarlo con el almidón para darle visos azules a la ropa blanca (DE LA HIRE 1730: 673), reproducido al pie de la letra en la Enciclopedia de Diderot y d'Alembert en 1751 (DIDEROT; D'ALEMBERT, 1751: 282). Por supuesto también se ha utilizado añil para azular la ropa, como lo explica Savary des Bruslons en 1726, o azul de Prusia, como está documentado por Diderot y d'Alembert (DIDEROT; D'ALEMBERT, 1751: 277). Pero Savary especifica que el índigo se utilizaba, sobre todo, para la seda y la lana (SAVARY DES BRUSLONS, 1726, col. 357).

Para almidonar el lino y la batista recomienda "l'émail, ou l'azur d'Hollande" mezclado con el almidón (SAVARY DES BRUSLONS, 1726: col. 358). Y así aparece constantemente en la literatura, como por ejemplo la descripción de Noël Chomel (1633-1712), en su Dictionnaire oeconomique de 1743: "On appelle azur de Hollande l'émail que se prépara á Amsterdam, \& en quelques autres endroits des Provinces-Unies, il est plus propre pour le linge que pour la peinture. [...] Les curandiers ou blanchisseurs de toiles fines, disent donner le bleu à une toile, pour signifier la faire passer dans une eau, où ils sont fait dissoudre un peu d'amidon avec de l'émail où azur de Hollande" (CHOMEL, 1743: col. 231). Una explicación más detallada ofrece el autor en su capítulo titulado "Blanchi" (CHOMEL, 1743: col. 212-215), donde propone el "azur d'Hollande, dont le plus gras \& le plus pâle est le meilleur, car il ne faut pas que les toiles ayant un bleu trop apparent" (CHOMEL, 1743, col. 214). Para el apresto de las batistas también recomienda almidón y esmalte pálido (CHOMEL, 1743, col. 214).

Jacobsson, en su diccionario tecnológico, de 1781, especifica que había dos suertes de "Blausel" (esmalte) para este fin, una clara y la otra oscura. La primera, que también se llamaba "Holländisches Blau" (azul de Holanda), la utilizaban las lavadoras para azular el lino fino y pañuelos. La segunda, la oscura, que había en diferentes grados, se mezclaba con el almidón (JACOBSSON, 1781: 223). 


\section{Arena secante}

Según Chaptal, en Alemania el esmalte se espolvoreaba sobre la tinta húmeda, para acelerar su secado (CHAPTAL, 1803: 135). Krünitz explica que se traía el "Streusand" (polvo de carta) de las montañas de Misnia, en toneles marcados con un $\mathrm{OH}$, que significaba el ordinario, o marcado con las letras MH, que era el esmalte de calidad media (KRÜNITZ, 1840: 661).

\section{Insecticida}

Schedel añade otra utilización, que puede explicar la aparición de esas grandes cantidades en las listas de comercio en América. Según él, los ingleses compraban esmalte alemán y enviaban anualmente varios miles de quintales al Caribe y a América, donde se empleaba como insecticida, espolvoreando las plantaciones de caña de azúcar (SCHEDEL, 1789: 115). Lamentablemente no da más explicaciones y resta por investigar cuál fue la sustancia activa en este uso, si no eran los residuos de arsénico o bismut.

\section{Colorante alimentario}

El empleo como colorante entre los confiteros está mencionado en el diccionario económico de Krünitz, quien remite a un artículo sobre "El elogio y la crítica de los regalos de Navidad y su efecto sobre la salud de los niños", de 1753, cuyo autor acota: "El uso de azul de almidón para colorear el mazapán, el azúcar y las muñecas de madera es sumamente nocivo para la salud" (KRÜNITZ, 1775: 614). Sin embargo, De Galdo, aún en 1858, repite este uso, explicando que la suerte más gruesa de los polvos azules sirve a los confiteros (DE GALDO, 1858: 287).

Parece desconcertante el consumo alimentario de este material, ya que se criticaba su presencia en la ropa como venenosa, además de su uso como insecticida, mencionado por Schedel (SCHEDEL, 1789: 115).

\section{CONCLUSIÓN}

El esmalte como pigmento se ha utilizado desde el el siglo XV en la pintura de caballete y la pintura al fresco y está bien documentado en los tratados de arte de la época. En los tratados españoles de pintura de Vicente Carducho, Francisco Pacheco o Antonio de Palomino, se describe bien su uso pero no se encuentra la denominación polvos azules. Este término fue detectado por Siracusano y Bruquetas en documentos mercantiles del virreinato del Perú. También surgió en el contexto del proyecto de investigación sobre las policromías de las tallas de las misiones guaraní-jesuíticas en el Paraguay. Pero siempre en documentos particulares y sin definición de la materia. Gracias 
a un tipo de fuentes escritas, hasta ahora no suficientemente aprovechadas en este contexto, la literatura tecnológica de la ilustración, la cual describe procesos enteros de producciones tecnológicas, y en nuestro caso la producción del vidrio de cobalto y sus diferentes grados de pulverización, elucidaron los muchos diversos usos del material en la época, aparte de los de la pintura. Usos tan disímiles y hoy día por lo general olvidados como lo fueron para pintar casas, porcelana, vidriar locería, para el apresto y el blanqueo de textiles y de ropa, como insecticida, para el oficio de los confiteros y como arena secante. Estas numerosas aplicaciones explican las enormes cantidades de polvos azules halladas en la documentación mercantil de aquel tiempo. Otra clase de fuentes escritas hasta ahora no debidamente consultadas son los diccionarios europeos del comercio, que describen las calidades diferentes que había en el mercado y también mencionan los usos variados. Comparando ejemplares de distintos países, llama la atención la similitud del vocablo en las diversas lenguas, como "poudre bleu" o "powder blue" y confirma una vez más que el término polvos azules corresponde al vidrio de cobalto molido. Aun está por hacer el estudio filológico sobre las diferentes denominaciones de las distintas suertes del vidrio de cobalto pulverizado en las diversas lenguas, regiones y aplicaciones. 
AHN, Madrid,

\section{CONSEJOS-JUROS,544,N.31}

[fol. 1r]

[izquierda: ]

D[o]n Diego de Egan de Nación

Irlandés:

Traslado

De la Zedula de S[u] M[a]g[esta]d en que le conzede facultad de poder mudar

y establecer en la

Villa de Leganes

la fabrica de Añil

Afinado que puso

en la de Vilvao =

1741

[derecha :]

D D

M[a]r[ave]d[í]s y franquezas

30 Oct[ubr]e de 1741

[centro:]

El Rey = Por quanto por D[o]n Diego de Egan de Nacion Yrlandes, y vecino de la villa de Vilbao, se me ha representado que en el año de

1736, ofreció establezer en España la fabrica de Añil Afinado, que hasta entonzes no la hubo, y sirbe para lustrar la ropa blanca, mejor que con los Polbos azules que se venden á este fin, y vienen de Payses estrangeros, los que tienen la contigencia de que con ellos puede perjudicarse la salud, y las ropas á que se aplicasen, lo que no sucedería con el Añil, por no componerse de los simples impuros de que se hacen áquellos, y tener la calidad de servir del mismo modo para dar el color de Perla, cuia experiencia hizo de órden de mi Real Junta de Comercio, y

fol. $1 v$ de Moneda, en presencia de Personas inteligentes; Y que haviendome suplicado le permitiese el establecim[ien]to de esta nueba fabrica,

y le concediese diferentes franquicias para ella, y el Añil q[u]e

fabricase, ofreci-

endo vender es-

te genero a me-

nos precio que lo venden los Estrangeros,

fui servido dispensarle por cedula de 26 de sep[tiemb]re de 1738 , el Privilegio para que por termi-

no 10 años, puediese establezer en estos mis Reynos la referida fabrica de Añil Afinado, sin que otra Persona alguna lo fabricase sin su permiso, y así mismo el fuero pasibo de la citada mi Real Junta, en todo lo perteneciente a su fabrica; y el que pudiese poner mis Reales Armas, sobre la Puertas de ella; en cuyo supuesto pasó á Yrlanda, á, solicitar operarios por no encontrarlos en españa, y conseguidos que fueron se restituyó á Vilbao, donde la estableció, a costa de muy crecidos gastos hasta ponerla en estado de que trabajasen

\section{[fol. $2 r$ ]}

oficiales en ella, y tener enseñado á un mozo español, como constó por informe del corregidor de aquella villa y que mediante ser la principal franquicia que necesitava, la de transportar a mi corte de Madrid por qualquier parte de mi Reyno el Añil Afinado, libre de d[e]r[ech]o y venderle sin pagar otros algunos; me suplicó, despues, fuese servido conzederle, asi esta, como las demas franq[uicia]s y exempciones dispensadas á otras fabricas, para que no se le siguiese el conocido perjuicio de malbaratar, por no poder conducir a Madrid 100, arrobas de Añil, que tenia fabricadas en Vilbao; Y visto en la referida mi Real Junta con lo que sobre todo expuso mi Fiscal, me hizo presente en consulta de 2 de Junio del año proximo pasado lo que sela ofrecía, y parecia, y por resoluzion a ella, He venido en conceder (como por la presente concedo) al referido $\mathrm{D}[\mathrm{o}] \mathrm{n}$ Diego de Egan, por tiempo de 5, años, las gracias de que pueda poner Lonjas en la expresada

[fol. 2v]

mi Corte de Madrid, y en otras qualesquiera Villas, y Lugares, o ferias de estos mis R[ey] nos

(á excepcion de los de las Yndias) en que pue-

da vender el Añil Afinado, libre de Alcavalas, y cientos, $y$ demas $\mathrm{d}[\mathrm{e}] \mathrm{r}[\mathrm{ech}] \mathrm{os} \mathrm{y}$ que en la conducion de este genero sea tambien libre de todos $\mathrm{d}[\mathrm{e}] \mathrm{r}[\mathrm{ech}]$ os de

Puertas, Aduanas, Portazgos, Puentes, y demas contribuciones Reales, ó, municipales, haciendo constar para este goze con Guias, ó, testimonios de ser el referido Añil Afinado, hecho en su misma fabrica, $y$ venderse en las Lonjas de su quenta, y a menos precio del que le vende el estrangero, con la calidad de que para poder entrar a el goze de las expresadas gracias, se ubiere de allanar á mudar la citada fabrica en lo interior de estos R[ey]nos por tener incombeniente conzederselas para la que tenia en d[ic]ha villa de Vilbao; $Y$ haviendose combenido en ponerla en la villa de Leganes de la Jurisdiccion de Madrid y trabajarse en ella, el

[fol. 3r] mencionado Añil Afinado. Por tanto, para que tenga el devido cumplimento la expresada mi Real resoluzion; He tenido por vien, 
dar la presente por la qual mando a la Jus-

ticia de la villa de Leganes

no pongan embarazo, ni im-

pedimento alguno al dicho

$\mathrm{D}[\mathrm{o}] \mathrm{n}$ Diego de Egan, para que

en ella plantifique la citada fabrica, y asi mismo mando, a los Presidentes, y Oydores,

de mis Consejos, Chancillerias y Audienz[ia]s

Asistente, Regentes, Governadores, Ynten-

dentes, Corregidores, Alcaldes mayores, y

ordinarios de estos mis R[ey]nos y señorios, y

á ótros qualesquier tribunales, Ministros

y Personas á quienes en qualquier manera,

toque, o tocar pueda el cumplimiento de

las expresadas gracias que hé concedido

al expresado D[o]n Diego de Egan, para la

fabrica de Añil Afinado que há de poner

en la citada villa de Leganes, que luego

que les sea presentada esta mi R[ea]l Cedula,

ó, su traslado, signado del es[criba]no publico en ma-

nera que haga fée, la guarden, cumplan,

[fol. 3v]

y ejecuten; hagan guardar, cumplir, y eje-

cutar en todo, y por todo, segun y como en ella se contiene, sin hir ni permitir que Persona alguna de qualquier estado, ó calidad que sea, ó ser pue-

da, con pretexto

causa, ó, motibo

que tengan, ó, ale-

guen tener, alteren su disposizion durante

el citado t[iem]po de los 5 años, por que se las concedo, con adbertencia de que cumplidos que sean, no há de poder continuar sin nueba prorrogazion mia; Y que qualquiera Persona que contrabenga en todo, ó, parte de ello, incurra en la pena de 500, Ducados de vellon en que desde luego le doy por incurso, y condeno, y se le sacarán, con ejecuzion á disposizión de la mencionada mi Real Junta de Comercio, y de
Moneda, por la qual se procedera a lo demas que aya lugar en derecho, que asi es mi voluntad; Y que de esta cedula se tome la razon en las contadurías Generales de Valores, y Distribuzion de mi

\section{[fol. 4r]}

Real Haz[ien]da en el termino de dos meses, de su

fecha y no haciendolo en ellos queden nulas estas gracias, y en las demas partes q[ue] combenga. $\mathrm{F}[\mathrm{ec}]$ ha en $\mathrm{B}[\mathrm{ue}] \mathrm{n}$ Retiro á treinta de octubre de mil setecientos quarenta y uno $=$ Yo el Rey $=$

Por mandado del Rey nuestro señor $=$ Don Blas

Martinez Lopez =

[diferente letra manuscrita:]

Es copia de su orig[ina]l de q[ue] se ttomo la Rason en la

contt[adurí]a G[ene]ral de la Distribucion M[adri]d de Dez[iemb]re

del $1741=\mathrm{D}[\mathrm{o}] \mathrm{n}$. Miguel Lorenzo Masero = [rúbrica] 


\section{BIBLIOGRAFÍA}

- BARRY, D. (1826) Noticias Secretas de América sobre el estado naval, militar y político de los reinos del Perú y provincias de Quito, costas de Nueva Granada y Chile; [...]. London: R. Taylor, 1826

- BECKMANN, J. (1792) Beyträge zur Geschichte der Erfindungen, vol. 3. Leipzig: Paul Gotthelf Kummer, 1792

- BOHN, G. C. (1726) Des wohlerfahrnen Kaufmanns anderer Theil, oder Neu-eröffnetes Waaren-Lager. Hamburg: Theodor Christof Felginer, 1726

- BOHN, G. C.; NORRMANN, G. P. H. (1805) Gottfried Christian Bohns Waarenlager, oder Wörterbuch der Produkten- und Waarenkunde [...], vol. 1. Hamburg: Carl Ernst Bohn, 1805

- BOMARE, de (1764a) Dictionnaire Raisonné Universel d'Histoire Naturelle, vol. 1. Paris: Didot, Musier, de Hansy, Panckoucke, 1764

- BOMARE, de (1764b) Dictionnaire Raisonné Universel d'Histoire Naturelle, vol. 4. Paris: Didot, Musier, de Hansy, Panckoucke, 1764

- BOWLES, G. (1775) Introducción a la Historia Natural de España. Madrid: Francisco Manuel de Mena, 1775

- BRABO, F. J. (1872) Inventarios de los bienes hallados, a la expulsión de los Jesuitas [...]. Madrid: M. Rivadeneyra, 1872

- BRACHERT, T. (2001) Lexikon historischer Maltechniken. München: Callwey, 2001

- BRUQUETAS GALÁN, R. (2010) Colores de artificio: comercio y producción en España hasta 1800. En EGIDO, M. DEL; KROUSTALLIS, S. (ed.) Fatto d'archimia: Ios pigmentos artificiales en las técnicas pictóricas. Madrid: Secretaría Gral. Técnica. Centro de Publicaciones. Ministerio de Educación, Cultura y Deporte, 2010, pp. 69-84

- BRUQUETAS GALÁN, R. (2002) Técnicas y materiales de la pintura española en los Siglos de Oro. Madrid: Fundación de Apoyo a la Historia del Arte Hispánico, 2002

- BRUQUETAS GALÁN, R. (2009) Técnicas y materiales en la pintura limeña de la primera mitad del siglo XVII: Angelino Medoro y su entorno. Revista de arte Goya, n. ${ }^{\circ}$ 327,2009 , pp. 144-161

- CHAPTAL, J.-A. (1796) Élémens de Chymie. 3. ed. Paris: Deterville, 1796, vol. 2

- CHAPTAL, J.-A. (1803) Elementos de química (trad. al castellano por Antonio Lorente). Madrid: García y Compañía, 1803, vol. 2

- CHOMEL, N. (1743) Supplement aus Dictionnaire oeconomique, vol. 1. Paris: Veuve Estienne, 1743

- CROEKER, J. (1721) Der zu Oel-Farben / Mahlerey und zu vielen andern Curieusen Wissenschafften wohl anführende Mahler [...]. Frankfurt, Leipzig: Heinrich Christoph Cröcker, 1721

- DE ARRIAGA, J. (1621) Extirpación de la idolatria del Pirú. Lima: Gerónnimo de Contreras, 1621

- DE GALDO, M. M. J. (1858) Los tres reinos de la naturaleza. Museo Pintoresco de Historia Natural. Madrid: José Rodríguez, 1858, vol. 9

- DE LA HIRE, P. (1730) Traité de la pratique de la peinture. En Mémoires de l'Académie royale des sciences. Paris: Compagnie des Libraires, 1730, vol. IX, pp. 637-730

- DE ULLOA, A.; JUAN, J. (1806) A voyage to South America, describing at large the Spanish Cities [...] (John Adams trad.). London: John Stockdale, 1806, vol. 1

- DELAMARE, F. (2013) Blue pigments. London: Archetype, 2013

- DELORMOIS, M. (1791) Arte de hacer las indianas de Inglaterra (trad. por Suárez). Madrid: Imprenta Real de la Gazeta, 1791

- DIDEROT, D.; D'ALEMBERT, J. B. (1751) Encyclopédie, ou Dictionnaire raisonné des sciences, des arts et des métiers. Paris: Briasson; David; Le Breton; Durand, 1751, vol. 2

- EMMERLING, E.; GRAMATKE, C. (2019) Die polychromen Holzskulpturen der jesuitischen Reduktionen in Paracuaria, 1609-1767. Kunsttechnologische Untersuchung unter Berücksichtigung des Beitrags deutscher Jesuite. München: Technische Universität München, 2019, vol. I y II

- GESTIS-STOFFDATENBANK GESTIS-Stoffdate nbank, Gefahrstoffinformationssystem der Deutschen Gesetzlichen Unfallversicherung [en línea] <http://gestis. itrust.de> [Consulta: 10/01/2019]

- GONZÁlEZ DE SALCEDO, P. (1729) Tratado Jurídico político del contrabando. Madrid: Juan Muñoz, 1729

- GRAMATKE, C. (2010) Drei spanische maltechnische Texte des Barock. Kommentierte Übersetzung ins Deutsche der Passagen aus Vicente Carducho "Diálogos de la pintura," (1633), Francisco Pacheco "Arte de la pintura" (1649) und Antonio Palomino "El museo pictórico y escala óptica" (1715-24). <https:// www.hfbk-dresden.de/fileadmin/user_upload/Down loads/Lehre-Forschung/Studiengaenge/Restaurierung/ Diss/Diss_Gramatke_2009.pdf> [Consulta: 25/06/2019]

- GRAMATKE, C. (2019) Einheimsche Materialien in der Skulpturenproduktion nach dem "Paraguay natural ilustrado" von P. José Sánchez Labrador (1771-1776). En EMMERLING, E.; GRAMATKE, C. (ed.) Die polychromen Holzskulpturen der jesuitischen Reduktionen in Paracuaria, 
1609-1767. Kunsttechnologische Untersuchung unter Berücksichtigung des Beitrags deutscher Jesuiten. München: Technische Universität München, 2019, vol. I, pp. 157-172

- HAMMER, P. (2004) Das Sächsische Blaufarbenwesen und der Handel mit Kobaltfarben - nach Unterlagen der Bücherei der Bergakademie Freiberg. En Cultural Heritage in Geosciences, Mining and Metallurgy. Leiden: 2004, pp. 108-117

- HARLEY, R. D. (1970) Artists' pigments, c. 16001835: a study in English documentary sources. London: Butterworths, 1970

- JACOBSSON, J. K. G. (1781) Technologisches Wörterbuch. Berlin: Friedrich Nicolai, 1781, vol. 1

- KRÜNITZ, J. G. (1775) Oeconomische Encyklopädie. Berlin: Joachim Pauli, 1775, vol. 5

- KRÜNITZ, J. G. (1840) Dr. Johann Krünitz's ökonomischtechnologische Enzyklopädie. Berlin: Paulsche Buchhandlung, 1840, vol. 175

- KUNCKEL, J. (1679) Ars Vitraria experminetalis oder vollkommene Glasmacher-Kunst. Frankfurt, Leipzig: Christoph Güntern, 1679

- LEYES (1776) Tomo quinto de las leyes de recopilación, que contiene los libros séptimo, i octavo. Madrid: Imprenta Real de la Gazeta, 1776

- LARRUgA, E. (1788) Memorias políticas y económicas sobre los frutos, comercio, fábricas y minas de España [...]. Madrid: Antonio Espinosa, 1788, vol. 3

- LEWIN, B. (1958) Descripción general del reino del Perú, en particular de Lima. Rosario, Perú: Instituto de Investigaciones Históricas, 1958

- LUDOVICI, C. G. (1741) Allgemeine Schatz-kammer der Kauffmannschafft oder Vollständiges Lexion aller Handlungen und Gewerbe. Leipzig, Johann Samuel Heinsius: 1741, vol. 1

- MACQUER, P. (1764) Dictionnaire de chymie, contenant la théorie et la pratique [...]. Paris: Lacombe, 1764, vol. 1

- MARPERGER, P. J. (1702) Das in Natur- und KunstSachen Neu-eröffnete Kauffmanns-Magazin. Hamburg: Benjamin Schillern, 1702

- MONTENEGRO COLÓN, F. (1843) Geografía General para el uso de la Juventud de Venezuela. Caracas: Imprenta de Damiron y Dupouy, 1834, vol. 3

- MORTIMER, T. (1810) A general dictionary of commerce, trade, and manufactures; exhibiting their present state in every part of the world; and carefully comp. from the latest and best authorities. London: Richard Phillips, 1810
- NEMNICH, P. A. (1797) Waaren-Lexicon in Zwölf Sprachen. Hamburg: Nemnich, 1797, vol. 1

- POSTLETHWAYT, M. (1757) The Universal Dictionary of Trade and Commerce, Translated from the French of the Celebraded Monsier Savary [...]. London: John Knapton, 1757, vol. 1

- REAl ACADEMIA ESPAÑOLA (1726) Diccionario de la lengua castellana, en que se explica el verdadero sentido de las voces, [...]. Madrid: Imprenta de Francisco del Hierro, 1726

- REAl ACADEMIA ESPAÑOLA (1739) Diccionario de la lengua castellana, en que se explica el verdadero sentido de las voces, [...]. Madrid: Herederos de Francisco del Hierro, 1739

- ReAl acAdemia española (1770) Diccionario de la lengua castellana compuesto por la Real Academia Española. Madrid: Ibarra, 1770

- SÁNCHEZ ESPINOSA, G. (2002) La obra del naturalista Guillermo Bowles y la política editorial del gobierno ilustrado. Dieciocho: Hispanic Enlightenment, vol. 25 (2), 09.2002, pp. 255-280

- SÁNCHEZ LABRADOR, J. (1771) El Paraguay Natural Ilustrado, Noticias de la Naturaleza del Pais con la explicacion de Phenomenos Physicos Generales y Particulares: [...]. MS, ARSI, signatura Paraq16

- SAVARY DES BRUSLONS, J. (1726) Dictionnaire universel du commerce. Amsterdam: Jansons á Waesberge, 1726, vol. 1

- SCHEDEL, J. C. (1789) Johann Christian Schedels neues und vollständiges Waaren-Lexikon. Offenbach: 1790, vol. 1

- SCHEDEL, J. C. (1814) Johann Christian Schedels neues und vollständiges, allgemeines Waaren-Lexikon. 4. edición. Offenbach: Carl Ludwig Brebe, 1814, vol. 1

- SELDES, A.; BURUCÚA, J. E.; MAIER, M.; JÁUREGUI, A.; SIRACUSANO, G. (1999) Los pigmentos azules en la pintura sudamericana (1610-1780). Journal of the American Institute for Conservation, JAIC [en línea], vol. 38, n. ${ }^{\circ} 2$, 1999, Article 1. pp. 100-123 <http://cool.conservation-us. org/jaic/articles/jaic38-02-001.html> [Consulta: 11/09/2018]

- siracusano, G. (2005) El poder de los colores. Buenos Aires: FCE, 2005

- SUÁREZ, M. J. (1778) Memorias instructivas, y curiosas sobre agricultura, comercio, industria, economía, química, botánica, historia natural, \&c. Madrid: Pedro Marín, 1778 vol. 2

- SUÁREZ, M. J. (1780) Memorias instructivas, y curiosas sobre agricultura, comercio, industria, economía, química, 
botánica, historia natural, \&c. Madrid: Pedro Marín, 1780, vol. 4

- TERREROS Y PANDO, E. (1788) Diccionario castellano con las voces de ciencias y artes y sus correspondientes en las tres lenguas francesa, latina e italiana. Madrid: Viuda de Ibarra, 1788, vol. 3

- VAlLAdARES DE Sotomayor, A. (1788) Semanario erudito, que comprehende varias obras ineditas, criticas, morales, instructivas, politicas, historicas, [...]. Madrid: Blas Román, 1788, vol. 11

- ZIMMERMANN, C. F. (1746) Ober-Sächsische BergAcademie: in welcher die Bergwercks-Wissenschaften nach ihren Grund-Wahrheiten untersuchet, und nach ihrem Zusammenhange entworffen werden. [...]. Dresden, Leipzig: Friedrich Hekel, 1746, vol. 1

- ZIMMERMANN, M. (1752) Mémoire sur la manière dont le saffre ou la couleur bleue tirée du cobalt se fait en Saxe. En Art de la verrerie, de Neri, Merret et Kunckel. Paris: Durand; Pissot, 1752, pp. 589-600

\section{ARCHIVOS}

- AGI Archivo General de Indias, Sevilla

- AGN Archivo General de la Nación, Buenos Aires

- AHN Archivo Histórico Nacional, Madrid

- ARSI Archivum Romanum Societatis lesu, Roma 